\title{
Coaching effectiveness within competitive youth football: youth football coaches' and athletes' perceptions and practices
}

Fernando Santos, Nuno Corte-Real, Leonor Regueiras, Cláudia Dias, Thomas J. Martinek \& António Fonseca

To cite this article: Fernando Santos, Nuno Corte-Real, Leonor Regueiras, Cláudia Dias, Thomas J. Martinek \& António Fonseca (2018): Coaching effectiveness within competitive youth football: youth football coaches' and athletes' perceptions and practices, Sports Coaching Review, DOI: 10.1080/21640629.2018.1459356

To link to this article: https://doi.org/10.1080/21640629.2018.1459356

曲 Published online: 04 Apr 2018.

Submit your article to this journal $₫$

Q View related articles $\sqsubset$

View Crossmark data ¿ 


\title{
Coaching effectiveness within competitive youth football: youth football coaches' and athletes' perceptions and practices
}

\author{
Fernando Santos ${ }^{\mathrm{a}}$, Nuno Corte-Real ${ }^{\mathrm{a}}$, Leonor Regueiras ${ }^{\mathrm{b}}$, Cláudia Dias ${ }^{\mathrm{a}}$, Thomas \\ J. Martinek ${ }^{c}$ and António Fonseca ${ }^{a}$
}

${ }^{\text {aS }}$ chool of Higher Education of Porto and Viana do Castelo, Faculty of Sports, University of Porto, Porto, Portugal; bPhysical Education Department, Nun'Alvres Institute, Santo Tirso, Portugal; 'Department of Kinesiology, University of North Carolina, Greensboro, NC, USA

\begin{abstract}
Competitive youth sport can provide solid grounds for positive youth development (PYD). However, there is need to understand if coaches are facilitating these types of outcomes. The purpose of this study was to analyze how competitive youth sport is used to facilitate PYD. The participants in this study were four youth football coaches and 19 adolescent athletes from competitive leagues at north of Portugal. Data were collected through semi-structured interviews, field notes and nonparticipant observations. The majority of the coaches communicated appropriately and facilitated positive interactions with youth athletes. Nevertheless, the participants did not implement an explicit approach towards the development of confidence, character, connection and competence (i.e., 4 C's) which has been linked to less PYD outcomes. Performance outcomes in certain moments superseded PYD ones. Moving forward, coaches need to comprehend how they can use their interpersonal knowledge to integrate the 4 C's within competitive youth sport.
\end{abstract}

\section{ARTICLE HISTORY}

Received 7 May 2017

Accepted 22 March 2018

\section{KEYWORDS}

Positive youth development; coaching context; coaches' knowledge; athlete's outcomes

In certain cases competitive youth sport is automatically linked with positive developmental outcomes such as increase in self-confidence, personal and social development, empathy for others, and physical development (Fraser-Thomas, Côte, \& Deakin, 2005). For instance, Lacroix, Camiré, and Trudel (2008) conducted semi-structured interviews with youth coaches who believed their athletes could attain positive developmental outcomes by participating in sport activities. However, these authors also stated coaches had difficulties mentioning strategies and concrete situations used to facilitate youth development that is connected to effective coaching literature. Based on this notion, competitive youth sport has 
also been linked to some negative outcomes such as antisocial behaviours that may lead to dropout and disengagement (Fraser-Thomas, Côté, \& Deakin, 2008). May (2001) conducted an ethnographic study with a high school sports team and studied how competitive youth sport can lead to negative developmental outcomes due to the contradictory goals of winning at all cost and promoting positive developmental outcomes. Most research within the sports science community gives a different perspective on the statement all sport is good" and raises the following question: How can competitive youth sport participation lead to positive developmental outcomes?

Over past decades positive youth development (PYD) has become a commonly used framework by researchers and practitioners to understand youths developmental process and how coaches should operate to facilitate positive developmental outcomes and help youth flourish (Lerner, Almerigi, Theokas, \& Lerner, 2005; Santos et al., 2016a). Consequently, PYD aims to prepare youth for the social challenges related to adult life. A variety of different frameworks and models associated to a PYD approach have been developed with implications on how competitive youth sport may facilitate positive developmental outcomes. For example, the teaching personal and social responsibility model developed by Donald Hellison has been extensively used among researchers and physical education teachers (Martinek \& Hellison, 2009). With this model coaches develop objectives and responsibility-based strategies to promote respect for others, participation and effort, autonomy, leadership and transference to other life domains. This model has been mainly applied within physical education-based settings with underserved youth and it has emerged as an effective model to foster personal and social responsibility development (Blanco, Delgado-Noguera, \& Escartí-Carbonell, 2013). Other models (e.g. Petitpas, Cornelius, Raalte, \& Jones, 2005) have also been developed to conceptualise how PYD should be integrated into competitive youth sport programs and to help coaches develop a deliberate approach towards PYD.

Hence, various models such as the one proposed by Hellison (2003) present several setting features key for planning competitive youth sport programs that foster psychosocial development as this is their primary focus. Although these models and frameworks provide specific guidelines for youth sport coaches to deliberately facilitate PYD outcomes, they do not encapsulate how PYD may be integrated as a part of effective coaching. Existing understandings of what effective coaching is (e.g. Bennie \& O'Connor, 2011) have offered different interpretations and alluded to the mechanisms that may lead to positive outcomes in and through competitive youth sport. For example, Bennie and O'Connor (2011) presented an effective coaching model within the Australian professional sport context which highlighted the need to analyze several sport contexts for model adherence (e.g. competitive youth sport). In addition, Jowett (2017) showed how coaches' interpersonal knowledge and coach-athlete relationships are instrumental for effective coaching. The same researcher also indicated the need to reflect on how effective 
coaching frameworks may integrate the need for coaches to foster PYD outcomes explicitly. However, information on how coaches' integrate PYD in their coaching practice within competitive youth sport and foster a vast array of athletes' outcomes is still scarce.

Despite the complex nature of coaching and facilitating PYD, it is possible that coaches can enable PYD outcomes (Collins, Gould, Lauer, \& Chung, 2009). For instance, Camiré, Trudel, and Forneris (2012) conducted interviews with 9 coaches and 16 student-athletes and reported that coaches prioritised PYD. Gould, Collins, Lauer, and Chung (2007) interviewed 10 high school football coaches that prioritised PYD in their coaching practice and considered PYD compatible with performance outcomes. However, coaches face several challenges and are influenced by the social forces, objectives, value systems and stakeholders involved in a specific sports setting. These factors combined determine how coaches should operate to create a sports climate conducive to PYD outcomes (Coakley, 2016). Competitive youth sport represents a specific socio-cultural context that is characterised by a strong focus on sport skills development and game performance and, in many cases, this philosophy is shared by all the members of a competitive youth sport club (Camiré, 2015). The social forces in place reflected on the interaction between coaches involved in competitive youth sport and parents, other competitive youth sport coaches, and stakeholders such as team managers and general managers tends to exclude a PYD mandate and to value victories, records and game performance as socially accepted practices (Coakley, 2016).

Sports coaching can be considered a social process as coaches and athletes interact constantly within a specific coaching context that entails an intricate set of objectives, demands and outcomes. The outcomes attained (e.g. performance-related, developmental) depend on coaches' priorities, strategies and climate created, and on their overall coaching effectiveness. This is a complex process that includes a broad set of coaching skills needed to facilitate PYD, as well as deal with several challenges and social forces that might be overwhelming for some coaches. These challenges are such things as promoting a broad range of athletes' outcomes within competitive environments (Cushion, Armour, \& Jones, 2003). As a socio-cultural context, competitive youth sport and the social forces present are becoming, in certain cases, increasingly focused on "performance at all cost" which influences coaches' practices and might lead to negative developmental outcomes (Fraser-Thomas et al., 2005). The aforementioned research has proven valuable in furthering our understanding about youth sport coaches' role in facilitating PYD. However, most studies have mainly focused on coaches' (e.g. Bean \& Forneris, 2017) or athletes' (e.g. Camiré, Trudel, \& Forneris, 2009) perceptions about PYD. Few studies have attempted to understand how PYD could be integrated within competitive youth sport as part of an effective coaching framework through coaches' and athletes' perceptions and actual behaviors.

As stated previously, winning and performance outcomes in, some cases, undermine the will to pursue developmental outcomes (Camiré, 2015). In the 
case of competitive youth sport, coaches should strive to prioritise both domains in order to become effective (Santos et al., 2016b). These outcomes are not mutually exclusive and could be integrated into their coaching practice (e.g. Potrac, Brewer, Jones, Armour, \& Hoff, 2000). In competitive youth sport, which includes thousands of young players, a more complex reality exists whereas coaches need to facilitate PYD outcomes and also focus on performance outcomes. In fact, effective coaching is not solely related to PYD outcomes and strategies as it also encompasses a broad range of coaching skills and contextual factors that have not been considered in most studies (e.g. Flett, Carson Sackett, \& Camiré, 2016).

\section{Coaching effectiveness framework}

Throughout the past decade effective coaching has been conceptualised and discussed within the coaching science community in order to answer a central question: What constitutes effective coaching? (Denison, Mills, \& Jones, 2013). Previous effective coaching frameworks have mainly focused on coaches' behaviors as leaders and have not further explored the role played by the coaching context (i.e. competitive youth sport) and desired athletes' outcomes (Denison \& Avner, 2011). In fact, several researchers (e.g. Bennie \& O'Connor, 2011) have not considered PYD and coaching contexts as part of an effective coaching framework. Nevertheless, some researchers have considered, within an effective coaching framework, a vast array of outcomes that combine the need to develop a PYD mandate and a set of performance-related outcomes with the coaching skills necessary to foster these outcomes in a specific sport context (Côté \& Gilbert, 2009). It is paramount to acknowledge the existence of a more nuanced context within which coaches and the effectiveness of coaching could be considered in ascertaining the extent to which a range and variety of outcomes consistent with PYD are achieved (Flett et al., 2016). This approach enables a more comprehensive understanding about how to facilitate PYD without neglecting a broader set of components that influence coaching for PYD outcomes. Hence, this approach might advance our understanding of PYD within competitive youth sport.

Côté and Gilbert (2009) created a coaching effectiveness framework that considers the aforementioned factors and offers insight on the main components that should be in place for effective coaching: (a) coaches' knowledge; (b) athlete's outcomes; and (c) coaching context. The usefulness of Côté and Gilbert's (2009) framework as opposed to other frameworks resides on the fact it establishes the extent to which coaches should be able to elicit PYD outcomes in competitive youth sport settings considering a broader set of coaching skills and coaching context. First, these researchers highlight the need for coaches' to have interpersonal knowledge and maintain meaningful relationships with athletes and parents, and communicate effectively. In fact, competitive youth sport programs should provide opportunities for youth athletes to develop a broad range of skills within an appropriate environment and with proper support from parents and coaches 
(Petitpas et al., 2005). In addition, parents should align objectives with coaches to promote a broad range of skills including PYD-related ones (Camiré et al., 2009). However, in some cases coaches and parents may have differing views which can lead to negative developmental outcomes (Dorsch, Wilson, \& McDonough, 2015; Holt, Kingsley, Tink, \& Scherer, 2011). Second, Côté and Gilbert's (2009) understanding of effective coaching suggest that the outcomes that come from effective coaching are competence, confidence, connection and character. The 4C's have been presented as desired outcomes of youth development that include the need to learn sport skills within an appropriate environment, attain an internal sense of positive self-worth, maintain positive relationships within sport and other life domains, as well as respect others and create empathy (Bowers et al., 2010; Côté \& Gilbert, 2009). Finally, this framework also alludes to the role played by the coaching context (e.g. recreational, competitive) and how these social and cultural forces influence coaches' and athletes' behaviors (Gilbert \& Trudel, 2006).

Based on Côté and Gilbert's (2009) understanding of effective coaching, it is necessary to systematically integrate coaches' knowledge to increase athletes' confidence, competence, connections and character given the particular characteristics of a sport context (i.e. aims, age group, and coaching domain) (Côté \& Gilbert, 2009; Flett, Gould, Griffes, \& Lauer, 2013b). This framework offers a broader consideration of effective coaching and how it should contribute to PYD outcomes in competitive youth sport (Flett et al., 2016). In addition, there is a general consensus within the scientific community these components need to be tested in specific sport contexts such as competitive youth sport (Flett et al., 2016).

In sum, this framework was used in the present study to understand how coaches' develop a coaching approach and practice coherent with Côté and Gilbert's (2009) understanding of effective coaching, as well as athletes' outcomes attained through competitive youth sport. Considering the nature of competitive youth sport and a PYD approach, this framework provides a broad understanding of PYD as it captures a vast array of athletes' outcomes and coaching skills within competitive youth sport.

Therefore, three research questions based on Côté and Gilbert's (2009) framework drove this research: (a) How are coaches developing interpersonal knowledge in competitive youth sport to foster PYD?; (b) What athletes' PYD outcomes are attained through competitive youth sport?; (c) How are competitive sport contexts influencing athletes' PYD outcomes and coaches' interpersonal knowledge?

\section{Method}

\section{Context}

In Portugal, most adolescent youth athletes are involved in competitive youth sport contexts (Resende, Sequeira, \& Sarmento, 2016). In fact, there are more than 200 competitive football clubs located across the country and more than 2000 athletes (mainly male athletes) just in the north of Portugal (Portuguese 
Table 1. Coaches' and athletes' demographic profile.

\begin{tabular}{|c|c|c|c|c|c|}
\hline Code & Age & Gender & Years of experience & Level of education & Other sport experiences \\
\hline $\mathrm{A} 1$ & 14 & Male & 8 & High school student & No \\
\hline $\mathrm{A} 2$ & 14 & Male & 4 & High school student & Yes (Table Tennis) \\
\hline $\mathrm{A} 3$ & 14 & Male & 6 & High school student & No \\
\hline A4 & 15 & Male & 7 & High school student & No \\
\hline A5 & 14 & Male & 8 & High school student & No \\
\hline A6 & 14 & Male & 7 & High school student & No \\
\hline A7 & 15 & Male & 6 & High school student & No \\
\hline A8 & 14 & Male & 8 & High school student & $\begin{array}{l}\text { Yes (Basketball, Hockey } \\
\text { and Swimming)) }\end{array}$ \\
\hline A9 & 14 & Male & 8 & High school student & No \\
\hline A10 & 14 & Male & 6 & High school student & $\begin{array}{l}\text { Yes (Tennis and Swim- } \\
\text { ming) }\end{array}$ \\
\hline A11 & 13 & Male & 3 & High school student & Yes (Tennis) \\
\hline A12 & 14 & Male & 7 & High school student & No \\
\hline A13 & 14 & Male & 9 & High school student & Yes (Tennis) \\
\hline A14 & 14 & Male & 10 & High school student & Yes (Tennis) \\
\hline A15 & 14 & Male & 4 & High school student & Yes (Karate) \\
\hline A16 & 14 & Male & 6 & High school student & $\begin{array}{l}\text { Yes (Karate and Swim- } \\
\text { ming) }\end{array}$ \\
\hline A17 & 14 & Male & 6 & High school student & Yes (Tennis) \\
\hline A18 & 14 & Male & 10 & High school student & No \\
\hline A19 & 14 & Male & 8 & High school student & No \\
\hline $\mathrm{C} 1$ & 52 & Male & 18 & Bachelor in Management & Former Player (6 years) \\
\hline $\mathrm{C} 2$ & 29 & Male & 6 & $\begin{array}{l}\text { Masters' in Physical } \\
\text { Education }\end{array}$ & Former Player ( 9 years) \\
\hline $\mathrm{C} 3$ & 26 & Male & 7 & $\begin{array}{l}\text { Bachelor in Physical } \\
\text { Education }\end{array}$ & Former Player (17 years) \\
\hline $\mathrm{C} 4$ & 28 & Male & 8 & Masters' in Youth Sports & Former Player ( 15 years) \\
\hline
\end{tabular}

Institute of Sports, 2011). These contexts provide opportunities for youth athletes to compete every week at a regional and national level as performance is highly valued in order to provide recognition and titles to their clubs. Sport federations, universities and governmental agencies promote coach education programs to certify youth coaches as certification is mandatory to formally coach in Portugal (Resende et al., 2016). These programs are concerned with equipping coaches to facilitate PYD in competitive youth sport.

\section{Participants}

The participants in this study were four youth football coaches and nineteen adolescent athletes from youth football who were involved in competitive clubs located at north of Portugal (see Table 1 for demographic information). The average age of the coaches was approximately 34 years, ranging from 26 to 52 years of age, with an average of 10 years of coaching experience in competitive contexts, ranging from 6 to 18 years. All the coaches were certified under the National Coaching Certification Program. Coaches and athletes interacted $15 \mathrm{~h}$ per week in practices and competitive games. The average age of the athletes was 14 years, ranging from 13 to 15 years of age, with an average of 7 years of experience in competitive contexts, ranging from 3 to 10 years. 


\section{Procedure}

The review board of the University provided ethical clearance and permission to proceed with this research. A purposeful sampling technique (Sparkes \& Smith, 2014) was used to recruit coaches and their athletes. The criteria for inclusion were: (a) involvement in competitive youth sport settings; (b) at least one year of experience in the competitive youth sport; and (c) being certified. First, a technical director from the local football association provided a list of 10 coaches that fulfilled the mentioned criterion. In total, four coaches accepted participate in the study. Then, the coaches were used as key informants and provided a list of 19 players who played on their teams. The interviews with coaches and athletes were scheduled at a mutually convenient time and place, and conducted immediately after a traning session or game. No more data was collected since experiential saturation was achieved and no further meaningful coding could occur as stated by Silverman (2000).

\section{Instruments}

\section{Semi-structured interviews and nonparticipant observations}

This study included semi-structured interviews and nonparticipant observations. Each component of Côté and Gilbert's (2009) understanding of effective coaching was analyzed through the participants' perceptions and behaviors in order to capture coaches' efforts to develop these features and athletes' responses. (Denzin \& Lincoln, 2011). A pragmatic qualitative perspective was used (Creswell, 2003) as the researchers attempted to create a comprehensive portrait of the phenomena without any focus on one epistemological methodology reflected on one single point of view.

Prior to the observations, semi-structured interviews were conducted with coaches and athletes (see appendix for both interview guides) based on past research (Camiré, Trudel, \& Bernard, 2013). Pilot interviews were conducted with two coaches and two athletes who had similar characteristics. This process was used to ensure that questions were structured appropriately and to train the interviewer. No major changes were made to the initial interview guides (Table 2).

The interview guides were organised in four sections (Rubin \& Rubin, 2012). The first section included a series of demographic queries (e.g. age; highest level of

Table 2. Overview of themes and subthemes.

\begin{tabular}{ll}
\hline Themes & \multicolumn{1}{c}{ Subthemes } \\
\hline Coaches' interpersonal knowledge & Creating meaningful relationships \\
& Coaches as role models \\
Impact on athletes & Character \\
& Confidence \\
& Competence \\
Influence of the competitive context & Connection \\
\hline
\end{tabular}


education). Beforehand, a brief definition of PYD was provided to assure the participants understood the themes discussed throughout the interviews. The second, third and fourth sections aimed to understand coaches and athletes perceptions' regarding youth sports' role in promoting an appropriate context conducive to PYD outcomes, meaningful relationships and strategies towards PYD outcomes. Additional interviews were also conducted with coaches and athletes immediately after training sessions to probe about PYD-behaviors registered by the first author throughout a particular observation (e.g. How did you felt as a leader today?). These interviews provided insight on the PYD-behaviors described in the initial interviews and enable a deeper understanding of athletes' and coaches' observed behaviours at the end of a training session (Denzin \& Lincoln, 2011). The interviews with the athletes lasted on average $50 \mathrm{~min}$ ranging from 45 to $75 \mathrm{~min}$. On the other hand, the interviews conducted with the coaches lasted on average $75 \mathrm{~min}$ ranging from 56 to $83 \mathrm{~min}$.

Nonparticipant observations were conducted to provide further insight on the athletes' and coaches' perceptions about PYD through competitive youth sport, and analyze PYD-behaviors as they occur (Sparkes \& Smith, 2014). Sixty hours of observations (i.e. each coach was observed on four training sessions and one formal competitive game) were conducted throughout two months and 32 pages of field notes were taken by the first author. Each observed session lasted between 60 and $95 \mathrm{~min}$. In addition, a recording device was placed on two athletes in each training session and the coach in order to capture interactions and PYD-behaviors that could not be heard through direct observation (Creswell, 2003). These interactions were included in the field notes. However, in formal competitive games only the coach had the recording device, because the local football association and the referees rejected the clubs' request for the researcher to place a recording device on the athletes. Observer comments throughout the observations were also audio-recorded.

\section{Data analysis}

All the interviews were transcribed verbatim by the first author. In addition, the recordings obtained from either a practice, game, or observer comments were also transcribed verbatim. The interviews and excerpts from observation notes were jointly analyzed to create a comprehensive understanding of coaches' and athletes' perceptions and behaviors within each of the overarching themes that were derived from Côté and Gilbert's (2009) understanding of coaching effectiveness. This process (e.g. interviews, field notes) generated a total of 140 pages of single-spaced text. A thematic content analysis was conducted using the software NVivo10 (Sparkes \& Smith, 2014) as the transcripts were organised in 1003 meaning units that were combined in a hierarchical manner to represent the data-set. A deductive and inductive approach was used (Fereday \& Muir-Cochrane, 2006) to allow interpretation of the data in the light of previous studies but also to provide 
new insight. The three main themes were created deductively through Côté and Gilbert's (2009) understanding of coaching effectiveness (i.e. coaches' interpersonal knowledge, impact on athletes, influence of the competitive context) which guided the present study. The remaining subthemes derived through an inductive approach (e.g. absence of developmental objectives, coach-parent interactions). Additionally, a deductive approach was based on providing the participants with a PYD definition to understand the extent to which their perceptions and practices were related to PYD. The interviews conducted immediately after a training session or game to probe about PYD-behaviors derived from the observations as a data-driven approach was used in this case (Sparkes \& Smith, 2014). The themes emerging from these specific interviews were inductively analyzed. The quotes included in the results section were translated by the first author and reviewed by a bilingual personal to avoid interpretation errors. Codes were used to assure the anonymity of the participants (e.g. C7, coach 7; A2, athlete 2).

Several techniques were used to assure the quality of the research (Denzin \& Lincoln, 2011; Sparkes \& Smith, 2014). First, a reflexive journal was kept by the first author to register all the changes, challenges and solutions implicit to the data analysis, and to allow transparency. Second, a member checking technique was used with the coaches as the transcripts were sent back to the participants allowing them to make changes to the original transcripts. No major changes were made by the coaches. This procedure enabled an accurate report of coaches' perceptions and experiences within this research. In addition, a negative case analysis was used to portrait non dominant views from the participants. Finally, peer debriefing served the purpose of attained coherence exposing the analytic decisions made by the researcher to the other authors with the intent of reflecting on different approaches and explanations. The co-authors who were experts in PYD also provided insight throughout the analysis and writing of the manuscript.

\section{Results}

Analysis of the observational and interview data produced three higher order themes. One of these was the Coaches Interpersonal Knowledge. This theme included two lower order themes: (a) Creating meaningful relationships, (b) Coaches as role models. The second higher order theme was Impact on Athletes which included outcomes due to the PYD experience and strategies used by coaches. This theme also reflects athletes' displayed behavior that were both observed and stated that alluded to or appeared to develop PYD outcomes. These outcomes were related to the Four Cs: (a) Character, (b) Confidence, (c) Competence, and (d) Connection. The third higher order theme was the Competitive Context. This theme looked at how the competitive nature of youth sport influenced PYD. One lower order theme was included in this theme: (a) PYD and competitive youth sport. These high order themes were linked to the Four Cs and reflected features that contributed to a PYD climate. 


\section{Creating interpersonal knowledge}

\section{Creating meaningful relationships}

The coaches identified the importance of creating a meaningful relationships with athletes by demonstrating a caring attitude and having an appropriate set of communication skills. Coaches mentioned how they try to develop a close relationship with players: "It is important to care about players. We need to respect their feelings and maintain a friendship with them" (C4). Athletes also commented on how a close relationship with their coaches was important: "A good relationship with the coach is everything. It allows us to share our opinions, what we like to do, joke around and feel appreciated" (A6). This was observed as coaches tried to gain insight about athletes well-being, their personal life and motivations: "It was very positive to see the coach interacting with a player who has just returned from injury. The coach seemed concerned about his well-being. Saying - 'If you need anything tell me, I'm here to help"' (O10).

Many athletes believed the constant incentives by coaches were conducive to positive developmental outcomes. One athlete mentioned: "The coach is always trying to provide positive feedback. For example, I played as a defender, I wanted to change position but I was reluctant to do it. He was the one who motivated me to be a goalkeeper" (A3). The coaches claimed they tried to encourage players by providing positive feedback and using effective communication skills. Two coaches added: "I value my players attitudes. This is what moves me. I try to focus on their strengths and share a positive message" (C3) and "I told them 'Congratulations! All of you worked very hard in practice.' It is important to give them positive feedbacks" (C4). These applications were confirmed through the observations:

The coach speaks with players and attempts to motivate them by saying - "I can see you are getting better and better. My role is to help you and provide constant support. We just have to keep working hard to continue to achieve our goals!". (O11)

\section{Coaches as role models}

Coaches were viewed as important role models that could influence players' developmental experiences. One athlete mentioned how coaches could affect their behaviours: "When a referee makes a mistake he does not yell at him, just talks to him politely. We follow his example and respect the referee" (A10). Coaches also recognised their influence as role models. One coach alluded to how his actions reflect on the players: "Your model it's the most important. In one occasion one of my players got sent off. I did not have to force him to come forward and admit he was wrong, because he had my example of being always honest" (C1). These applications were observed as coaches in many cases represented positive role models to young players and influenced positively their behaviours:

The coach asks players to choose teams and helps a group of athletes by saying: "How many players does your team have? So you have all the players you need. See if someone needs help as I did with you guys" The athletes follow the coaches' positive example and help their teammates. (O8) 


\section{Impact on athletes}

\section{Character}

All the coaches and athletes believed the program could help foster character. For example, athletes described how conflicts were managed within the program and what changed in their conduct: "Before I was always yelling at other people, but now I am able to control myself and respect others" (A4). One coach also recognised the importance of speaking with players to promote respect: "We often use individual conversation as a strategy to foster respect. We try to be honest and direct with them" (C4). Another coach also stated: "We speak with them when they disrespect someone. Normally it works most of the times and they do not try it again" (C2). However, on a few occasions one coach yelled at players and struggled in facilitating respect for others: "The environment is quite tense at the moment as the coach yells at players who do not follow his rules - 'You have to do the warm-up now! What the fuck are you doing? Are you stupid or what?"' (O15).

Most participants mentioned there were opportunities to develop leadership skills:

The team captain helps the other players to get ready on time before a game. He is also responsible for choosing the players that will help him manage the material for practice and for organising the stretching part of the session. We do take advantage of this teachable moments. (C2)

However, some coaches stated that they did not pursue leadership in a deliberate manner: "I do not develop leadership. Why work this with them? They do not have to be leaders" (C3). Some athletes mentioned that not all players had the opportunity to improve their leadership skills: "Only a few players can improve these skills if they turn out to be good leaders. This is only for some players, not for all" (A16) and "This year I never had the opportunity to be a leader. Others had and improved it" (A18). Both comments were confirmed throughout the observations as coaches developed few activities to develop leadership (only three direct teaching strategies were registered) and mainly team captains had this responsibility:

The coach does not provide opportunities for athletes to develop leadership skills as athletes just follow their coaches' instructions. However, the coach asks an athlete to lead the cool down drill at the end of the session, because he cannot stretch and did not want to do it. There are no direct strategies towards leadership development. (O11)

\section{Confidence}

Most athletes claimed they were able to develop confidence and reported how they improved their sense of self-worth: "I have improved this aspect. For example, if I am in a very hard game I do not quit. I give my best to obtain the win. Previously I had difficulties in keeping engaged" (A8). Coaches also prioritised confidence in their coaching practice: "Confidence can be developed as any other skill. We need to speak with them and create opportunities for them to work on it. My players 
never quit" (C2). All the participants made it clear they believed competitive youth football allowed athletes to find a valued role within the group:

Before I entered the program I did not fit in because I did not like to speak to anyone. However, after I started to play here I felt more comfortable and this helped me feel included in the team. (A5)

Observations demonstrated that coaches explicitly developed confidence and character:

In this drill, the coach provides opportunities for athletes to become more confident, develop new skills and tries to give unconditional support to help them strive by saying "You can do it! Keep going at it!". There is a positive climate as athletes feel challenged and are able to fulfill the coaches' expectations. (O9)

Many athletes mentioned they got more autonomous throughout the program: "In the beginning I was not able to make proper decisions. I did many mistakes but now I can make better decisions. I'm the one who has to make decisions so I had to learn that" (A16) and "For example, I have the opportunity to choose teams. I need to make the best decision I can" (A9). Most coaches tried to foster autonomy by helping players reflect on their decisions and providing opportunities for them to make choices. One coach stated: "They have to decide if they are going to pass the ball to A, B or C. To reflect about their choices is important and have the opportunity to experience it in practice and live with the consequences" (C3). The coaches did not mention any other strategies to develop autonomy. These applications were not completely confirmed through observations. In most cases coaches had other covert objectives:

The players arrive and choose which exercise they will do. They can choose the exercise and use the material available. However, the coach says - "Do whatever you wish while I prepare the first exercise. I need more time to prepare it". (O18)

\section{Competence}

Coaches promoted competence by creating an appropriate environment for youth athletes to develop sport-specific technical and tactical skills. For example, a coach, mentioned how he tried to foster a positive, fun and enjoyable environment and create a proper context for sports development:

We try to do exercises they enjoy to promote a positive and successful sport experience.

Even if an exercise is useful for learning how to play the game it has to be fun also. This is the foundation for choosing a particular activity. (C4)

Another coach also prioritised fun and performance skills in his coaching practice: "I usually say to players that we should have fun in practices and games. I try to focus on fun activities that can promote healthy competition within the team" (C3). Athletes also commented on the importance of having fun: "I have fun in the program. I have opportunities to achieve success, score goals and play with my teammates. I enjoy it here" (A15). Observations showed that athletes demonstrated positive reactions to the activities proposed by their coaches. It was clear that fun and enjoyment were prioritised. However, in certain moments coaches 
experienced difficulties in integrating these features with teaching performance skills. Coaches pressured players to obtain performance outcomes which lead to negative outcomes:

The coach becomes very upset when an athlete misses a goal opportunity and says "You have to shoot on goal exactly here! Why do I have this drill here? Fuck! Score a goal here! The coach pressures players to attain performance outcomes. The athletes start to show signs of frustration and bait other players". (O14)

\section{Connection}

Athletes reported that they established relationships with their teammates within a positive climate: "I started to find my place here and make friends. Since I came to the program I feel included within the group" (A6). Many coaches also stressed the importance of facilitating a positive connection with others. One coach stated "In our program athletes have to work together, fall and get right up which can be useful to create an inclusive environment for all" (C4). Observations demonstrated a positive environment and meaningful connections with coaches and athletes:

It is interesting to see that athletes arrive early and use this moment to speak about their school life, the previous game and include everyone in this conversation. You know - they say "You played well yesterday", "We will win the next game, everyone is in shape". The coach arrives, joins the conversation and poses questions to the players that have not spoken until this point. The environment is inclusive even in a decisive stage of the season. (O7)

All the participants in this study envisioned the transfer of positive developmental outcomes to other life domains. This competitive youth football context enabled connection as positive bonds and social relationships were fostered outside sport: "In Physical Education I apply what I have learned. I stay with weaker players and I help them improve" (A1) and "The respect I have for my coach I apply to my parents. In school I also do the same and help a student in need as I would do in practice" (A10). Coaches supported these claims and mentioned how they believed young players could use these skills and apply them outside competitive youth sport: "What they learn here helps them outside the program because they have to solve problems and relate to one another" (C3). This application was not witnessed through the observations as coaches rarely (only two direct teaching strategies were registered) implemented direct teaching strategies towards connection.

Based on athletes' perceptions, coaches and parents worked together towards PYD. Athletes believed coaches and parents pursued similar PYD outcomes and communicated appropriately: "My parents want me to be more responsible in different situations. The coach wants the same" (A10). However, coaches portrayed a different scenario and believed there was tension between parents' objectives and their efforts to create meaningful relationships and facilitate PYD: "The parents are not either protective or supportive. They influence negatively youth's development because they just want to win" (C1). The same coach added: "Sometimes 
athletes are influenced by parents' strategies outside football. If they do not work towards PYD and have priorities such as trying to teach their kids technical skills or contradict coaches things may start to fall apart".

Another coach showed his frustration about the different priorities parents have and highlighted the need to find common grounds within PYD: "If the parents at home do not work towards positive developmental outcomes what we do here it's irrelevant! This is not happening. We need to find a way to work alongside parents" (C3). Observations also displayed the negative influence parents have on players:

It is an intimating scenario. The parents are insulting the referee and telling the players what to do. Saying - "Pass the ball, don't be selfish", "You are a clown". The coach is becoming very frustrated and turns to the stands and says "Shut up all of you". (O17)

\section{Influence of the competitive context}

\section{PYD and competitive youth football}

According to all coaches and athletes, competitive youth football represented an enriched context that could be used to facilitate a range of developmental outcomes. Athletes believed competitive youth football could be extremely important in their developmental process: "Other contexts are not as important in promoting youth development because there is no competition. In competitive sports things have ten times more importance" (A12). One coach stated: "An athlete who is involved in competitive football might not value other contexts. The fact they have competition, results and objectives gives more importance to our efforts towards youth development" (C1). No observed behaviours were associated with this category. All coaches and athletes believed athletes had the opportunity to succeed despite inter-individual differences and attain PYD outcomes, and performance outcomes through competitive youth football.

Unfortunately, two coaches mentioned they only provided meaningful experiences in practices and not in formal competitive games due to competitive nature of this context and the social forces at stake who influenced to focus only on game performance: "For instance, today we did an exercise that involved two stops so we could switch teams and everyone had the same opportunity to play in different settings and positions. In games is different because we need results." (C4) and "In the games we try to call all the players throughout the season, but sometimes they do not leave the bench. We do not change the starting eleven, because we have to perform and win" (C1). Athletes recognised the existence of a fair reward system despite the competitive nature of this context. One athlete stated: "Everyone has a chance in practice. However, it won't last forever. You have to work hard, because some will play and others just won't. We need to win and play well." (A9). However, one player mentioned he did not have the opportunity to play despite working hard in each practice as he felt excluded: "I feel I'm a part of the team in practices but in games it's like I don't even matter" (A3). These applications were witnessed 
throughout the observations as coaches prioritised performance objectives in games and provided opportunities for all players to have a positive experience in practices. However, some players were excluded in certain moments due to the need to attain performance outcomes which had a negative impact on them: "The game is very competitive at this moment. There are 20 min remaining and most players haven't left the bench. They seem excited for the team but at the same disappointed for not having a chance to play and succeed" (O20).

All of the participants referred to the importance of performance objectives as the social forces within competitive youth sport drove coaches to focus mainly on winning: "Since I joined the team our objective is to win all games. For example, this week the coach stressed the importance of winning four games" (A11). However, some coaches struggled in aligning PYD and performance outcomes and mentioned that only performance objectives are shared with players constantly. One coach stated the objective for this season: "This year our objective is to win and reach the first division. The players are aware that we want to play well and win" (C3). In contrast, athletes recognised that their coaches did not systematically set objectives directed at facilitating outcomes such as competence, confidence, connection, and character. One athlete indicated: "Normally the coach does not set objectives associated with my personal development. However, this could help. I would be more concerned about this as it happens with performance objectives" (A17).

Two coaches corroborated the absence of explicit PYD objectives within competitive youth football: "I do not try to share with players that 'look today we will work on certain values'. I do not think about it in that way. It comes implicitly" (C4). The focus on performance objectives was witnessed through the observations as developmental objectives were not considered on a consistent basis:

The coach begins the session by saying - "Look guys, we have to improve our passing skills today to improve our performance. This is the goal". The coach only sets expectations related to performance outcomes. Other types of objectives seem to be addressed explicitly. (O6)

\section{Discussion}

Based on Côté and Gilbert's (2009) framework, the purpose of this study was to analyze, from coaches' and athletes' perceptions and practices, how competitive youth football is used to facilitate PYD outcomes. This study provided a novel insight on how effective coaching may include PYD outcomes and strategies, but also other coaching skills within a specific sport context. This holistic perspective on the coaching process helps further our understanding about the setting features that influence a PYD mandate within competitive youth sport. Methodologically, this study also provided a multidimensional approach as coaches' and athletes' perceptions and actual behaviors were captured. 


\section{Coaches' interpersonal knowledge}

Regarding coaches' knowledge of how to foster relationships, the majority of the coaches demonstrated interpersonal knowledge by communicating appropriately and facilitating positive interactions with their players through an inclusive and intrinsically motivating environment. It was clear from interviews and observations of coaches interpersonal knowledge' that they were able to nurture meaningful relationships and influence athletes' PYD-behaviors. Maintaining close relationships with young players and being a positive role model have also been considered important characteristics of youth sport coaches that may facilitate positive developmental outcomes (Camiré et al., 2012; Hellison, 2003). For example, Hellison (2003) and Petitpas et al. (2005) mentioned that coaches should take advantage of teachable moments, use individual conversations and positive incentives to develop an emphatic relationship with youth athletes. Several researchers have also highlighted the need for coaches' knowledge of how to foster relationships in order to create pleasurable environments and meaningful relationships so positive developmental outcomes can be attained (Martinek \& Hellison, 2009). Youth sport coaches need to consider this feature of Côté and Gilbert's (2009) understanding of coaching effectiveness and intentionally create opportunities to foster positive coach-athlete relationships and attempt to use modelling an importance source for attaining PYD outcomes. However, in the present study coaches' interpersonal knowledge needed to foster positive coach-parent interactions was limited.

Parents represented negative influences on youth development due to the conflicting objectives set by coaches and parents. From observations, it was clear they focused only on performance, baiting players and referees (Dorsch et al., 2015). However, it was interesting to verify that athletes believed parents and coaches need to work together towards positive developmental outcomes. The conflicting objectives of coaches and parents should be addressed as competitive youth football should provide opportunities for them to align efforts and set clear expectations regarding desired outcomes (Allen, Rhind, \& Koshy, 2015; Knight \& Holt, 2012). In order to reach what Côté and Gilbert (2009) suggested as coaching effectiveness and coaches' interpersonal knowledge, coaches should be able involve parents and set common developmental objectives which were challenging for the participants in this study. Coaches would benefit from aligning PYD strategies and objectives which enhance athlete's developmental experiences and outcomes. Therefore, it is paramount for coaches to share their pedagogical approach, PYD objectives, and to suggest possible strategies that may be used in other life domains. To accomplish this endeavor, coaches might promote meetings with parents and athletes and engage them in an intentional approach towards PYD (ProjectSCORE!, 2017). Future research endeavors should understand how an intervention program focused on coach-parent relationships may produce more developmental outcomes as it will also enable a better comprehension of the challenges faced within coach-parent relationships. 


\section{Athletes' outcomes}

Regarding the second component of Côté and Gilbert's (2009) framework, several studies have highlighted the fact competitive youth sport programs can facilitate positive developmental outcomes through an explicit approach (Collins et al., 2009; Gould et al., 2007; Jung \& Wright, 2012). In this study, coaches fostered a PYD climate but, in most cases, struggled in implementing PYD strategies and having an explicit focus on the 4C's. Holt et al. (2017) have mentioned in one their proposed hypothesis that a PYD climate aligned with a deliberate approach may enable more PYD outcomes. Recent studies have highlighted how coaches adopt an implicit approach to PYD because its less time consuming and demanding (Chinkov \& Holt, 2015; Turnnidge, Côté, \& Hancock, 2014). However, a question needs to be raised in this case: are coaches working explicitly towards outcomes viewed as more relevant to achieve performance outcomes? Coaches may have adopted an explicit approach to the development of character and competence because respect for others and performance skills (i.e. learning sport specific skills) were viewed as critical to attain performance outcomes. Coaches should understand how all athlete's outcomes reflected in Côté and Gilbert's (2009) framework may impact a team's performance and contribute to positive experiences in sport. Additionally, coaches could adopt an intentional approach towards PYD that encompasses specific objectives, strategies and activities focused on the $4 \mathrm{Cs}$ that might emerge embedded with other performance objectives they are pursuing within competitive youth sport. Future research should analyze how personal and social skills may influence performance in competitive youth sport programs.

Competitive youth sport was portrayed as extremely important for youth development due to the meaning inherent of being part of a team and to the intensity attributed to the developmental experiences lived in this context (Camiré, 2015). This critical role played by competitive sport programs has been highlighted in previous research (Camiré, 2015; Coakley, 2016; Strachan, Côté, \& Deakin, 2011). However, this study indicated that athletes only had opportunities to succeed and have meaningful experiences in practices. In competitive games, coaches valued victories and used a reward system based on players' efforts and skill level. This has been considered one of the challenges of implementing youth sport programs in these coaching contexts (i.e. competitive settings) (Whitley, Forneris, \& Barker, 2015). Even though most athletes believe the reward system was fair and provided solid grounds for youth development there is the need to redefine how competitive games and victories can represent valuable contexts in which youth can learn how to become more confident, respect others, connect with others, be competent and attain leadership skills (Danish, Forneris, Hodge, \& Heke, 2004; Fraser-Thomas et al., 2005). Through the present study it was possible to distinguish between how PYD occurs in practices and competitive games. Coaches behaviors were influenced by the social forces existent within competitive youth sport that had performance outcomes the main priority which may compromise adherence to 
Côté and Gilbert's (2009) understanding of effective coaching and impact the other components included in this framework. If competitive sport programs have a tremendous impact on youth's developmental process they should be used to its full potential and should not be a vehicle for exclusion (Strachan, Côté, \& Deakin, 2009). Coaches need to understand how they can attain performance outcomes and incorporate the 4C's in their coaching practice as all athlete's needs for inclusiveness and opportunities to attain success should be considered. Dealing with the pressures of competitive games might be too overwhelming for some coaches as a sense of pedagogical coherency needs to be reflected in both practices and games. In addition, coach education programs could use Côté and Gilbert's (2009) framework to inform coaches about how to integrate these outcomes based on a broader understanding of what effective coaching is and entails. This specific framework enabled to capture the extent to which PYD outcomes were achieved and pursued by coaches as it considers critical elements that are part of a PYD mandate and, in this case, provided a valuable insight into competitive youth football.

\section{Coaching context}

Regarding the third component of Côté and Gilbert's (2009) framework, in the present study coaches and athletes behaviors were influenced by the coaching context in where conflict between performance outcomes and PYD existed. From the observations, it was possible to conclude that two coaches focused only on performance outcomes and used negative teaching strategies such as yelling and bating players which had been found in previous research studies (Flett, Gould, Griffes, \& Lauer, 2013a; May, 2001). That is, the competitive environment and the social forces present seemed to have a negative influence on promoting those elements that support positive PYD conditions. This was disappointing in that Holt et al. (2017), using a grounded theory approach, presented several hypotheses that alluded to the fact that attaining PYD outcomes in and through sport will facilitate transfer and enable youth to thrive and connect to their communities. Coaches are often pressured to obtain records and win regularly in competitive youth sport which might undermine the balance that can be attained between performance and developmental outcomes (Camiré, 2015). The social forces within competitive youth sport and a subculture of winning at all cost impacts coaches ability to pursue PYD outcomes (e.g. Santos et al., 2017). Findings indicated that some coaches mentioned only performance objectives although athletes raised the need for developmental objectives that could guide them and produce more PYD outcomes.

In the present study, coaching contexts shaped how coaches operated to attain outcomes related to the $4 \mathrm{Cs}$ and presented interpersonal knowledge. Frameworks that conceptualise coaching contexts within effective coaching could be considered in coach education programs as coaches may not be equipped to deal with 
the pressures and challenges of coaching in competitive youth sport. There might be the need to included specific contents and strategies that may be useful for these coaches. In addition, the present study corroborated the notion that coaches consider players' mistakes in practices and games are a stressor that in some cases leads to negative teaching strategies (Forneris, Camire, \& Trudel, 2012; McCallister, Blinde, \& Weiss, 2000). Previous studies have emphasised the need to use a strength-based approach and focus on personal developmental (Camiré et al., 2013; Petitpas et al., 2005). Future studies should also analyze how coaches work with other stakeholders by focusing on how their philosophies and practices differ from one another. This step is critical in order to design intervention programs (e.g. education programs) to promote coaching effectiveness focused on their needs and challenges.

\section{Practical implications}

This study presents several practical implications for coaches and coach education programs. First, coaches' could strive to foster a deliberate approach towards a variety of athletes' PYD outcomes that should be viewed as paramount for youth's developmental process in and through sport. In order to attain what Côté and Gilbert define as effective coaching, coaches need to comprehend how they can use their interpersonal knowledge to integrate confidence, character, connection and competence within a specific sport setting. Second, coaches' need to present interpersonal knowledge and establish positive relationships with other stakeholders' (e.g. parents, technical directors) to create solid grounds for more PYD outcomes within competitive youth sport. Performance and PYD outcomes can coexist and there is need for coaches, parents and sport administrators to work together towards these outcomes, and design clear objectives, strategies and activities aimed at PYD outcomes. Third, coach education programs could also provide opportunities for coaches to learn how to facilitate a broad range of skills, deal with the social forces that exist in competitive sport and help them envision an explicit approach towards PYD. Finally, coaches and competitive youth sport clubs could also educate parents on how they can provide solid grounds for youth development and enact on Côté and Gilbert understanding of effective coaching.

\section{Conclusion}

The present study used Côté and Gilbert understanding of effective coaching and provided new insight on a variety of key features relevant to attain PYD outcomes in competitive youth football which increases our understanding about how PYD is operationalized in this specific context. Competitive youth football has the necessary potential to provide opportunities for PYD. Football clubs also play an important role in facilitating positive developmental outcomes because they entrust coaches with a particular set of objectives (e.g. developmental, 
performance), enable their initiatives and set moral boundaries. However, the nature of the coaching context may undermine coaches' effectiveness because they fail to use interpersonal knowledge to facilitate outcomes consistent with the $4 \mathrm{Cs}$.

\section{Disclosure statement}

No potential conflict of interest was reported by the authors.

\section{References}

Allen, G., Rhind, D., \& Koshy, V. (2015). Enablers and barriers for male students transferring life skills from the sports hall in the classroom. Qualitative Research in Sport, Exercise and Health, 7(1), 53-67.

Bean, C. \& Forneris, T. (2017). Is life skill development a by-product of sport participation? Perceptions of youth sport coaches. Journal of Applied Sport Psychology, 29, 234-250.

Bennie, A., \& O'Connor, D. (2011). An effective coaching model: The perceptions and strategies of professional team sport coaches and players in Australia. International Journal of Sport and Health Science, 9, 8-104.

Blanco, P., Delgado-Noguera, M., \& Escartí-Carbonell, A. (2013). Analysis of teaching personal and social responsibility model-based programmes applied in USA and Spain. Journal of Human Sport \& Exercise, 8(2), 427-441.

Bowers, E., Li, Y., Kiely, M., Brittian, A., Lerner, J., \& Lerner, R. (2010). The five cs model of positive youth development: A longitudinal analysis of confirmatory factor structure and measurement invariance. Journal of Youth Adolescence, 39, 720-835.

Camiré, M. (2015). Reconciling competition and positive youth development in sport. STAPS, 109, 25-39.

Camiré, M., Trudel, P., \& Bernard, D. (2013). A case study of a high school sport program designed to teach athletes life skills and values. The Sport Psychologist, 27, 188-200.

Camiré, M., Trudel, P., \& Forneris, T. (2009). Parents' perspectives on the practice of high school sport in a Canadian context. Qualitative Research in Sport \& Exercise, 1(3), 239-257.

Camiré, M., Trudel, P., \& Forneris, T. (2012). Coaching and transferring life skills: Philosophies and strategies used by model high school coaches. The Sport Psychologist, 26, 243-260.

Chinkov, A., \& Holt, N. (2015). Implicit transfer of life skills through participation in Brazilian jiu-jitsu. Journal of Applied Sport Psychology, 1-15.

Coakley, J. (2016). Positive youth development through sport: Myths, beliefs, and realities. In N. L. Holt (Ed.), Positive youth development through sport (2nd ed., pp. 21-33). London: Routledge.

Collins, K., Gould, D., Lauer, L., \& Chung, Y. (2009). Coaching life skills through football: Philosophical beliefs of outstanding high school football coaches. International Journal of Coaching Science, 3(1), 29-54.

Côté, J. \& Gilbert, W. (2009). An integrative definition of coaching effectiveness and expertise. International Journal of Sports Science \& Coaching, 4(3), 307-323.

Creswell, J. (2003). Research design: Qualitative, quantitative and mixed methods approaches (2nd ed.). Thousand Oaks, CA: Sage.

Cushion, C., Armour, K., \& Jones, R. (2003). Coach education and continuing professional development: Experience and learning to coach. Quest, 55, 215-230.

Danish, S., Forneris, T., Hodge, K., \& Heke, I. (2004). Enhancing youth development through sport. World Leisure, 3, 38-49. 
Denison, J., \& Avner, Z. (2011). Positive coaching: Ethical practices for athlete development. Quest, 63, 209-227.

Denison, J., Mills, J., \& Jones, L. (2013). Effective coaching as a modernist formation. In P. Potrac, W. Gilbert, \& J. Denison (Eds.), Routledge handbook of sports coaching (pp. 133-145). Abingdon: Routledge.

Denzin, N., \& Lincoln, Y. (2011). The SAGE Handbook of qualitative research (4th ed.). Los Angeles, CA: Sage.

Dorsch, T. E., Wilson, S. R., \& McDonough, M. H. (2015). Parent goals and verbal sideline behavior in organized youth sport. Sport, Exercise, and Performance Psychology, 4(1), 19-35.

Fereday, J., \& Muir-Cochrane, E. (2006). Demonstrating rigor using thematic analysis: A hybrid approach of inductive and deductive coding and theme development. International Journal of Qualitative Methods, 5(1), 2-11.

Flett, M. R., Carson Sackett, S., \& Camiré, M. (2016). Understanding effective coaching: Antecedents and consequences. In R. Thelwell, C. Harwood, \& I. Greenlees (Eds.), The psychology of sports coaching: Research and practice (pp. 156-169). London: Routledge.

Flett, M., Gould, D., Griffes, K., \& Lauer, L. (2013a). Tough love for underserved youth: A comparison of more and less effective coaching. The Sport Psychologist, 27, 325-337.

Flett, M. R., Gould, D., Griffes, K. R., \& Lauer, L. (2013b). Tough love for underserved youth: A comparison of more and less effective coaching. The Sport Psychologist, 27, 325-337.

Forneris, T., Camire, M., \& Trudel, P. (2012). The development of life skills and values in high school sport: Is there a gap between stakeholder's expectations and perceived experiences? International Journal of Sport and Exercise Psychology, 10(1), 9-23.

Fraser-Thomas, J. L., Côte, J., \& Deakin, J. (2005). Youth sport programs: An avenue to foster positive youth development. Physical Education and Sport Pedagogy, 10(1), 19-40.

Fraser-Thomas, J., Côté, J., \& Deakin, J. (2008). Understanding dropout and prolonged engagement in adolescent competitive sport. Psychology of Sport and Exercise, 9(5), 645-662.

Gilbert, W. \& Trudel, P. (2006). The coach as a reflective practitioner. In R. Jones (Ed.), The sports coach as educator: Re-conceptualising sports coaching (pp. 113-129). New York: Routledge.

Gould, D., Collins, K., Lauer, L., \& Chung, Y. (2007). Coaching life skills through football: A study of award winning high school coaches. Journal of Applied Sport Psychology, 19, 16-37.

Hellison, D. (2003). Teaching personal and social responsability through physical activity (2nd ed.). Champaign, IL: Human Kinetics.

Holt, N., Kingsley, B., Tink, L., \& Scherer, J. (2011). Benefits and challenges associated with sport participation by children and parents from low-income families. Psychology of Sport and Exercise, 12(5), 490-499.

Holt, N., Neely, K., Slater, L., Camiré, M., Côté, J., Fraser-Thomas, J., ... Tamminen, K. (2017). A grounded theory of positive youth development through sport based on results from a qualitative meta-study. International Review of Sport and Exercise Psychology, 10(1), 1-49.

Jowett, S. (2017). Coaching effectiveness: The coach-athlete relationship at its heart. Current Opinion in Psychology, 16, 154-158.

Jung, J., \& Wright, P. (2012). Application of Helisson's responsibility model in South Korea: A multiple case study of 'at-risk' middle school students in physical education. Agora para la Educación Física y el Deporte, 14(2), 140-160.

Knight, C., \& Holt, N. (2012). Recommendations for coaches on enhancing parental involvement in tennis. ITF Coaching and Sport Science Review, 20(57), 3-5.

Lacroix, C., Camiré, M., \& Trudel, P. (2008). High school coaches' characteristics and their perspectives on the purpose of school sport participation. International Journal of Coaching Science, 2(2), 23-42.

Lerner, R., Almerigi, J., Theokas, C., \& Lerner, J. (2005). Positive youth development a view of the issues. The Journal of Early Adolescence, 25(1), 10-16. 
Martinek, T., \& Hellison, D. (2009). Youth leadership in sport and physical education. New York, NY: Palgrave Macmillan.

May, R. (2001). The sticky situation of sportsmanship. Journal of Sport \& Social Issues, 25(4), 372-389.

McCallister, S., Blinde, E., \& Weiss, W. (2000). Teaching values and implementing philosophies: Dilemmas of the youth sport coach. Physical Educator, 57(1), 35.

Petitpas, A., Cornelius, A., Raalte, J., \& Jones, T. (2005). A framework for planning youth sport programs that foster psychosocial development. The Sport Psychologist, 19, 6-80.

Portuguese Institute of Sports. (2011). Estatísticas do desporto de 1996 a 2009 [Sports Statistics from 1996 to 2009].

Potrac, P., Brewer, C., Jones, R., Armour, K., \& Hoff, J. (2000). Towards an holistic understanding of the coaching process. Quest, 52, 186-199.

ProjectSCORE! (2017). About SCORE. Retrieved from http://www.projectscore.ca/about-score

Resende, R., Sequeira, P., \& Sarmento, H. (2016). Coaching and coach education in Portugal. International Sport Coaching Journal, 3(2), 178-183.

Rubin, H., \& Rubin, I. (2012). Qualitative interviewing: The art of hearing data (3rd ed.). Thousand Oaks, CA: Sage.

Santos, F., Côrte-Real, N., Regueiras, L., Dias, C., \& Fonseca, A. (2016a). O papel do treinador no desenvolvimento positivo dos jovens através do desporto: Do que sabemos ao que precisamos saber [Coaches' role in positive youth development through sport: From what we know to what we need to know]. Revista Iberoamericana de Psicología del Ejercicio y el Deporte, 11(2), 289-296.

Santos, F., Corte-Real, N., Regueiras, L., Dias, C., \& Fonseca, A. (2016b). Personal and social responsibility development: Exploring the perceptions of Portuguese youth football coaches within competitive youth sport. Sports Coaching Review, 6(1), 1-18.

Santos, F., Corte-Real, N., Regueiras, L., Strachan, L., Dias, C., \& Fonseca, A. (2017). Portuguese football coaches' role in facilitating positive development within high performance contexts: Is positive development relevant? International Sport Coaching Journal, 4(2), 147-161.

Silverman, D. (2000). Doing qualitative research: A practical handbook S.1. Thousand Oaks, CA: SAGE.

Sparkes, A., \& Smith, B. (2014). Qualitative research methods in sport, exercise and health: From process to product. New York, NY: Routledge.

Strachan, L., Côté, J., \& Deakin, J. (2009). An evaluation of personal and contextual factors in competitive youth sport. Journal of Applied Sport Psychology, 21, 340-355.

Strachan, L., Côté, J., \& Deakin, J. (2011). A new view: Exploring positive youth development in elite sport contexts. Qualitative Research in Sport, Exercise and Health, 3(1), 9-32.

Turnnidge, J., Côté, J., \& Hancock, D. J. (2014). Positive youth development from sport to life: Explicit or implicit transfer? Quest, 66, 203-217.

Whitley, M., Forneris, T., \& Barker, B. (2015). The reality of sustaining community-based sport and physical activity programs to enhance the development of underserved youth: Challenges and potential strategies. Quest, 67, 409-423. 